\title{
Use of on-line computers in experimental psychology: Hardware considerations
}

\author{
DAVID M. SARGENT \\ State University of New York College at Oswego, Oswego, New York
}

\begin{abstract}
A series of modules provide students with the basic skills to set up and use a computer to run psychological experiments. The modules include basic knowledge of AC/DC power supplies, relay switching, analog/digital conversion, integrated circuit board design and soldering, and elementary programming (FORTH and BASIC). These skills are then utilized to build an interface board and to design and run actual on-line experiments. The hardware orientation is combined with computer skills and experimental methodology to allow students to experience all stages of modern psychological experimentation.
\end{abstract}

Computer utilization in laboratory courses has taken a variety of directions including computerized tutorials and exercises (Eamon \& Butler, 1985; Hornby \& Anderson, 1988), simulations of psychology experiments either with numerical representations of behavioral results or with some type of screen graphics such as Simlabs (Queen's University Psychology Department, 1986) or PSYCHAID (Huffman, Vernoy, \& Williams, 1987), or software packages with experiments for students either to run or to redesign by way of a series of choices such as the Micro Experimental Laboratory (Schneider, 1988) software system. All of these procedures appear to be valuable and provide students with computer experience. It is hard to say, however, that any one method or methods will work the best given the wide variety of applications and course focuses (Eamon, 1988). In perusing the published papers on computer applications in teaching, it is readily apparent that few, if any, standards exist in laboratory methods or even in equipment used. The present on-line course does not attempt to alleviate any of these problems directly, but rather takes a different tactic. By not focusing on any specific computer or software package, the general interfacing techniques are examined and used in a basic computing system. This upper-division course examines computer-controlled psychological experimentation at a level intended to give the student a working knowledge of the underlying principles and necessary hardware skills for computer equipment interfacing. It is hoped that this basic knowledge will be upwardly compatible with different and newer systems that the student may encounter in the future.

\section{Purposes}

The primary purpose of the on-line computers in experimental psychology course is to familiarize the students

Address correspondence to David M. Sargent, Department of Psychology, State University of New York, Oswego, Oswego, NY 13126. with the current technology and give them the basic hardware and software skills needed to run psychological experiments. This upper-level course requires a background in experimental methodology, but does not require any specific computer experience.

The course is structured as a series of modules, each of which encapsulates a basic skill necessary for setting up a computer-based experiment. These modules include the fundamentals of electricity (relays, soldering, electronic debugging, and signal tracing), the binary system, programming languages (such as BASIC, FORTH, and C), differences in computers and operating systems, computer components, and peripheral compatibility. The students are provided with a rough schematic and are required to design and build an interface board to connect a computer (usually an S-100 system) to standard electromechanical equipment. This operation is then combined with their knowledge of experimental methodology to design modern experiments in a variety of psychological areas.

As the interface project progresses, the students and the instructor design several experiments together for human or nonhuman subjects (rats). These experiments utilize a variety of electromechanical components including rat operant chambers, human response keys and lights, and even M\&M candy dispensers. One or two experiments of each type are chosen to be implemented by small groups of students. With occasional guidance from the instructor, the students design and detail each experiment, write and debug the software, and connect and test the hardware. Each group then runs the experiment with either human or nonhuman subjects, collects data, and submits a finished paper. In this way, all aspects of the research are experienced along with the associated problems.

Relevant special topic modules, including analog to digital conversion, computer voice recognition, robotics, and artificial intelligence are inserted into the course, depending on the nature of the experimental projects chosen. Students thus complete the course with a broad range of skills and a basic understanding of the requirements for using computers in psychological experimentation. 


\section{Equipment and Software}

We are currently using three different systems: the North Star Horizon CP/M microcomputer with Electrohome monochrome graphics-driven Paragraphics and George Risk Industries keyboards, the Apple II and an IBM compatible. Each of the latter two systems interfaces with the A-Bus, an 8-channel input/output board that mounts in the computer, from Alpha Products. The S-100 bus in the North Star is compatible with a variety of third-party peripherals, such as the Paragraphics A/DD/A card and the Mountain Systems millisecond timer card. Although the system is limited to $64 \mathrm{~K}$ of memory, there is enough room for most types of experimental designs. Overall cycle time is kept to a minimum by using Paragraphic's FORTH (pgFORTH) programming language. One distinct advantage of pgFORTH is that each component part of the program/experiment can be tested individually as it is written, which greatly facilitates understanding and reduces programming frustration. Since pgFORTH is not a full-featured compiled language, time is not lost while the students wait for the latest revision of their program to be compiled. Standard $28 \mathrm{~V}$ electromechanical equipment is connected to the interface equipment, which allows for a large variety of experimental situations, but keeps the time spent on setup and fabrication to a minimum.

\section{Course Organization}

The on-line course has prerequisites of statistics and methodology in psychology, and requires that the students be aware of the specific controls and properties needed to construct psychological experiments. The course does not assume any previous hardware or software courses, or any electronics experience.

The initial modules orient the students to the basics of electricity, AC/DC, and the properties of relays. The students then develop a working knowledge of relay switching through class projects that use standard electromechanical equipment $(28 \mathrm{~V})$. At the same time, they also learn the basics of a simple programming language through projects in screen graphics.

Next, the students are ready to start construction of an interface panel to connect the electromechanical equipment to either the A-Bus digital input/output (I/O) or the Paragraphics $1 / 0$ board. The interface board is primarily an eight-channel switching device that utilizes optoisolator and peripheral driver-integrated circuits with the proper resistors and diodes. While this project is being wired and soldered, the class as a whole (usually 8-12 students) designs a basic experiment using rat subjects. The students then write the software needed for the daily trials of the experiment, debug and test each phase of the program, and run live subjects through the phases under the close supervision of the instructor. The results are then analyzed and reported in an American Psychological Association (APA)-style paper. Other experiments are then designed to use either rat or human (usually introductory students) subjects, and are carried out in the same manner. The semester usually allows for three such experiments. The students are evaluated on the basis of the experiment design and operation, the APA-style paper, and class and project participation. The class as a whole is required to finish and test its interface panel by the end of the semester.

\section{Fringe Benefits}

The hardware and software that is developed by the class is almost always used in experimental methods courses, where the students act as both subjects and experimenters in learning, memory, cognitive, and perception experiments. These experiments include such basic paradigms as the Sternberg (1966) memory experiment, a spatial learning task (using a lighted matrix of buttons), some signal detection tasks (using screen graphics), a mental rotation task similar to Shepard and Metzler (1971), a release from proactive inhibition procedure (Wickens, 1970), and a time-telling experiment utilizing graphic representations of analog and digital clocks in a reactiontime paradigm. Each interface panel is then used in research and for future on-line classes in experiments that have more than one computer station running at a given time. In this way, the class becomes self-reliant and can, at any time, upgrade gradually to more state-of-the-art equipment.

\section{Future Expansion}

We currently have an NSF-ILI grant application in progress to replace the North Star Horizon $\mathrm{CP} / \mathrm{M}$ machines with the Macintosh II system, complete with the MacADIOS interface from G. W. Instruments. The speed, memory, and color capabilities available in that system will expand the possibilities for the types of experiments that can be designed and run. In addition, software packages such as the LabVIEW system by National Instruments can be utilized to reduce the amount of time needed to learn basic programming and to get the students directly to the interfacing and experimental concerns.

\section{Conclusion}

The present on-line course has been successful over a number of semesters for both the students directly involved in the class and for other students and professors involved in research. The course provides a good capstone experience that culminates with the skills acquired in methodology and topics courses. The students also come away with several practical skills that are useful when working with computers either in experimental psychology or simply on a daily basis.

\section{REFERENCES}

Eamon, D. B. (1988). Problems with evaluation of courseware for instruction in psychology. Behavior Research Methods, Instruments, \& Computers, 20, 178-179.

EAMON, D. B., \& BUTLER, D. L. (1985). Instructional programs for 
psychology: A review and analysis. Behavior Research Methods, Instruments, \& Computers, 17, 345-351.

HoRnby, P., \& ANDERSON, M. (1988). Using computers in introductory psychology. Behavior Research Methods, Instruments, \& Computers, 20, 180-183.

Huffman, K., Vernoy, M., \& Williams, B. (1987). PSYChaID [Computer Program]. New York: Wiley.

Queen's University Psychology DePartment. (1986). Simlabs [Computer Program]. Mishawaka, IN: Soft Productions.
SCHNEIDER, W. (1988). Micro Experimental Laboratory: An integrated system for IBM PC compatibles. Behavior Research Methods, Instruments, \& Computers, 20, 206-217.

ShePard, R. N., \& MetZler, J. (1971). Mental rotation of threedimensional objects. Science, 171, 701-703.

SternBerg, S. (1966). High speed scanning in human memory. Science, $153,652-654$.

WiCKENS, D. D. (1970). Encoding categories of words: An empirical approach to meaning. Psychological Review, 77, 1-15. 